\title{
Advancement and Future Directions towards Herbal Treatment for Various Diseases
}

\author{
Usman Ghani ${ }^{1}$, Ammara Batool ${ }^{1}$, Hamza Rafeeq ${ }^{1}$, Muhammad Naeem ${ }^{1 *}$, Syed Saad ul Hassan Bukhari ${ }^{2}$, Hafiz Ahsan ${ }^{1}$, \\ Amna Naeem ${ }^{1}$, Sara Saddique ${ }^{1}$, Shahid Ali Chand ${ }^{3}$ \\ ${ }^{1}$ Department of Biochemistry, University of Agriculture, Faisalabad, 38000, Pakistan \\ ${ }^{2}$ Department of Theriogenology, University of Agriculture, Faisalabad, Pakistan \\ ${ }^{3}$ Department of Plant Pathology, University of Agriculture, Faisalabad, 38000, Pakistan
}

\begin{abstract}
DOI: $10.36348 /$ sjmps.2019.v05i11.003
| Received: 31.10.2019 | Accepted: 07.11.2019 | Published: 11.11.2019

*Corresponding author: Muhammad Naeem
\end{abstract}

\section{Abstract}

The purpose of review article is to find herbal drug for treatment of some diseases. Several side effects came from chemical drugs. Use of non-chemical, non-invasive natural remedies have no major adverse effect because contain naturally active biological components, therefore they have paying much attention within recent years. Possible usage of leaf extract of Papaya for treatment of dengue fever promising cure for dengue patients. Pomegranate contains high level of antioxidants which make it one of the best fruits for boosting blood count. Phenolic compound extraction from extra virgin olive oil has immune modulatory and anti-inflammatory effects in Systemic lupus erythematosus (SLE) patients. Wound healing properties are exerted from aloe Vera gel. Fenugreek seed best natural remedy for Poly ovarian cyst syndrome (POCS). Garlic and ginger are organosulfur compounds consisting upon its bio actives having an important role in cardiovascular diseases and cancer respectively.Nigella sativa recently demonstrates the role in diabetes mellitus. Allium cepa. L (Onion) contain phytochemicals that have antidiabetic, anticarcinogenic, anti-inflammatory, antibiotic, antioxidant, antimicrobial and antiplatelet effects on the human health.

Keywords: Dengue fever, Anemia, Systemic lupus erythematosus, EVOO, Hypertension.

Copyright @ 2019: This is an open-access article distributed under the terms of the Creative Commons Attribution license which permits unrestricted use, distribution, and reproduction in any medium for non-commercial use (NonCommercial, or CC-BY-NC) provided the original author and source are credited.

\section{INTRODUCTION}

Yearly Millions of individuals are susceptible to dengue and approximately 50-100 million each year are infected with dengue [2, 25]. This disease is transmitted through Aedes mosquito that is infected with dengue virus. Ingredients in leaf of papaya can prevent bone marrow destruction and enhances it capacity to produce platelets [75]. Recently many health beneficial effect are exhibited by various parts of pomegranate, biologically active compounds that contribute to antioxidant property are vitamins, phenolics, anthocyanins and minerals [8].

These health beneficial effects of EVOO have been attributed due to monounsaturated fats content, phenolic composites presence [20]. EVOO plays main role in cure of immune inflammatory Systemic lupus erythematosus (SLE) disease [10]. Leaves OF Aloe vera contain varied range of biologically active compounds and contains numerous beneficial properties antimicrobial, anti- oxidative, purgative, anti-inflammatory, antifungal, anti- helminthic, antiseptic and aphrodisiac [57]. Aloe vera gel not only enhance collagen synthesis it also does changes in cross linkage and composition of collagen due to which wound contraction and breaking strength of resulting shock tissues increase [55].

Ginger has ability to act vasoconstrictor this led toward hypothesis that bioactive compounds in ginger must have structural similarities to vasoconstrictor. Components present in ginger including 1-dehydro-[10]-gingerdione, [6]- gingerol, [6]-shogaol and [10]-gingerdione, are consider to act as potent anti-oxidant effect regarding migraines [15]. Onions' antidiabetic activity is exhibited due to its active constituents that exert multiple pharmacologic activities. The remarkable oral hypoglycemic action of onions has been identified, which is mainly due to presence of allyl propyl disulphide while other constituents such as quercetin and anthnocyanidin also play a main role [59].

The comprehensive mechanism of antihypertensivity of garlic involves reduction of oxidative stress reduces hypertension and related cardiovascular 
disorders.By inhibiting the activation of NF- $\mathrm{B}$ (a transcription factor involves in pathology of hypertension and atherosclerosis) in many types of cells including endothelial cells. By enhancement of $\mathrm{H}_{2} \mathrm{~S}$ and influencing the activity of cystathionine c-lyase. Currently fenugreek seed in combination with other natural products is used for diabetes and reduce weight. Medical study is done on effects of fenugreek in reduction of Poly ovarian cysts syndrome (POCS) symptoms, number and volume of ovarian cysts. Fenugreek seed extract used as adjuvant therapy with metformin, for treatment of POCS in women [60].

Natural products gain from plant source is good remedy for management and treatment of diseases. These herbs are easily available, effective, and affordable without having any adverse effect on health. Fruits, vegetables and spices contain important bio actives gives best alternative treatments used as a remedy for over hundreds of years all over the world. Biochemical and molecular studies of extracts gain from these amazing natural products are using as remedy due to their immense health beneficial effects and medicinal property [60]. The different components of the turmeric plant stand useful in handling of numerous diseases including arthritis, ulcers, neuroinflammation and cardiovascular disease.

\section{PAPAYA AS ANTI- DENGUE Overview of Dengue fever}

Dengue is most important arthropod-borneviral (arboviral) disease that is transmitted through mosquitoes that causes both illness and death in human beings $[62,2,25]$. Four serotypes that are antigenically distinct are designated as Dengue Virus (DNEV-1, DNEV-2, DNEV-3 and DNEV-4) [45]. Mild symptoms with headache, chills and hemorrhagic fever or serious with very high fever, even death, all are due to low platelet count [45]. One of the most frequently occurring feature in patients with dengue is thrombocytopenia remarked decrease in platelet count [37].

Thrombocytopenia is linked with reduced capacity of hematopoietic cells proliferation in bone marrow and increase destruction of platelet from peripheral blood might be due to autoimmune reaction [45]. Mechanism of thrombocytopenia is not clear. Suppression in bone marrow, immune mediated destruction and clearness of platelet are due to dengue virus infection [47].

Certain platelet type genes Arachidonate 12lipoxygenase (ALOX 12) too recognized as lipoxygenase (ALOX 12) help in megakaryocyte production and differentiation which lead to 12hydroxyeicosatetraenoic acid production and in that production of platelet [9] and Platelet-Activating Factor Receptor (PTAFR) gene expression in megakaryocytes indicate that it will probably be a forerunner for platelet production in addition it also involved in aggregation of platelet [67].

\section{Carica papaya}

Papaya (Carica papaya Linn) is specie of Caricaceae family, commonly known as paw-paw. Carica papaya has many medical benefits [76]. Carica papaya have potential to fight against dengue fever, it can be used due to its effects to treat thrombocytopenia condition in dengue fever [45]. Carica papaya leave extract found to increase platelet count significantly in early $24 \mathrm{hr}$. of consumption it increases white blood cell and neutrophil count also [67]. On dengue viralinfected plasma the leaf extract of papaya has dengue specific neutralizing effect that might exert defensive role on platelets [19].

\section{Components of papaya leave}

Papaya leaves contain numerous nutrients and phytoconstituents including phenolic compounds (ferulic acid, caffeic acid and chlorogenic acid) tannins, alkaloids (pseudocarpaine, dehydrocarpaine I and II, carpaine), cardiac glycosides, flavonoids (myricetin and kaempferol), saponins and enzymes which may have antioxidant and immune modulatory effects [76, 18].

\section{Papaya leaves extract for dengue fever}

Production of platelets is done by ALOX12 megakaryocyte genes that are expressed strongly in megakaryocyte [51]. Extract of C. papaya leaf increase ALOX12 [51] and PTAFR gene expression; both are accountable to produce platelets [31].

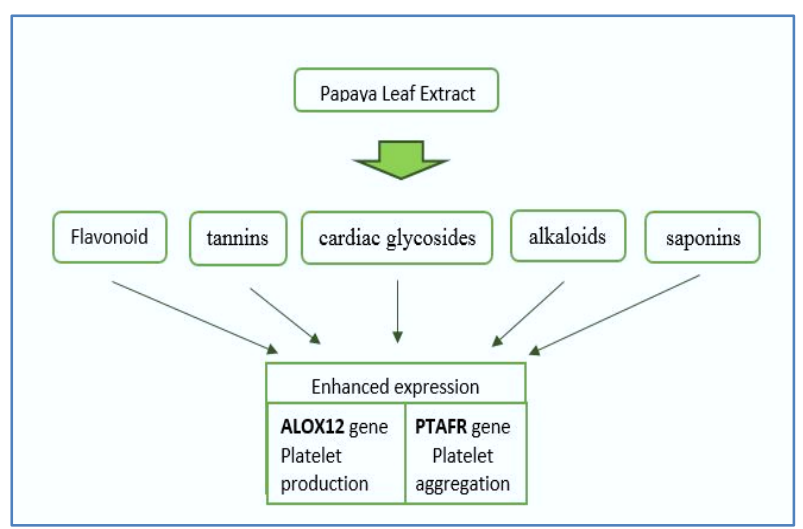

Fig-1: Active comments of papaya act upon platelet production genes

\section{Treatment of anemia with pomegranate}

Anemia is characterized by lack of enough healthy red blood cells and low concentration of hemoglobin $(\mathrm{Hb})$ [72]. Recent studies shown that oxidative species causes deregulation of blood cells. Condition of oxidative stress arises from disproportion between anti-oxidants and oxidants [63], when production of reactive oxidative species (ROS) exceeds to detoxifying capacity [72]. Oxidative stress lead to redox signaling destruction and damage of 
biomolecules [63], these cellular biomolecules including proteins, lipids and deoxyribonucleic acids are basic building blocks [72]. Pathogenesis of several diseases are based upon oxidative stress [72],[29]. Oxidative stress contributes to many other diseases including diabetes in which glucose uptake is impaired in muscles, fat impaired occur due to oxidative stress and insulin secretion from pancreatic $\beta$ cells decrease. Hypertension and atherosclerosis are also caused by oxidative stress which directly disturbs vascular wall cells [24]. Oxidative stress is as well causative agent for Alzheimer's disease (AD), it increases in aging, neurogenerative diseases and cancer as well [72].

In various diseased conditions antioxidants have positive effect as represented in many clinical studies, prevention of disease occur due to antioxidants [29]. Endogenous antioxidants are produced naturally inside human body, or these are taken from diet sources called exogenous antioxidants, example indule sulforafanes, anthocyanins, polyphenols, vitamin C, carotenoids and curcumin [52].

\section{Pomegranate Fruit}

Botanically pomegranate is known as Punica granatum. It belongs to Punicaceae family. Pomegranate have many nutritional values and medicinal assistances, these properties use to cure many diseases involving heart problems, stomach disorders, diabetes, osteoarthritis and anemia [27].

\section{Components of Pomegranate}

The fresh fruit juice contains $85.4 \%$ water and $15.6 \%$ dry constituent including sugars mainly glucose, fructose, Organic acids such as malic acid, and ascorbic acid, Citric acid bioactive substance include pectins, anthocyanins, polyphenols, vitamins and minerals [30].

\section{Nutritious pomegranate juice may boost the status of blood cells in human}

Regular Pomegranate Juice (PJ) Consumption for two weeks help to rise red blood cell (RBC) count, concentration of hemoglobin and hematocrit in healthy person. $\mathrm{RBCs}$ and $\mathrm{Hb}$ transport oxygen from lungs to tissues. Increase polyphenolic content in pomegranate Juice increase RBC resistance toward oxidative stress [77]. Recent study explain that polyphenols increased content in PJ prevent RBCs destruction due to reduced oxidative stress [41]. Plant polyphenols namely, the flavonoids initiate enzyme expression and catalytic activity that involve in Glutathione $(G S H)$ biosynthesis [44], level of Glutathione significantly increases in two weeks intake PJ [42]. Flavonoid component of pomegranate juice protects hemoglobin from oxidation which is caused by many factors such as hypochlorous acid [28].

Reduce RBCs destruction increases hematocrit level, in PJ high antioxidant concentration provide protection to RBCs and results in them reduce destruction [41].

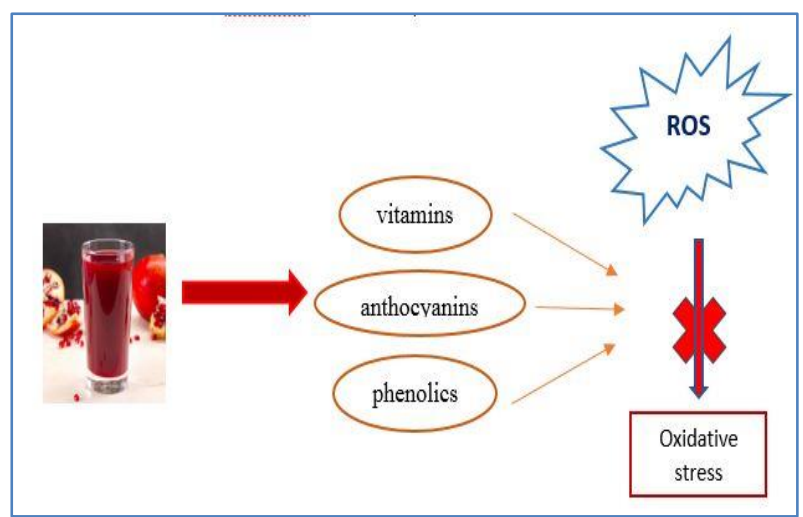

Fig-2: Major components of pomegranate as antioxidant

\section{Extra virgin olive oil (EVOO) for Systemic lupus erythematosus (SLE) \\ Extra virgin olive oil (EVOO)}

The key source of fat is Mediterranean diet is Extra virgin olive oil (EVOO) [58], based on chemical and sensorial properties extra virgin olive oil is top quality oil with least cases of chronic degenerative diseases and high life span are associated with Mediterranean diet [58].

Current study available on Extra virgin olive oil beneficial effects is that specific antioxidant properties and biological activates of phenolic contents in oil have capability against many diseases including immune-mediated inflammatory response (diabetes, obesity, rheumatoid arthritis, inflammatory bowel disease, atherosclerosis, cancer or neurodegenerative diseases among others [17].

\section{Components of Oil (EVOO)}

Consumption of extra virgin olive oil described as bioactive diet due to presence of biologically active compounds, high nutritious value and specific composition of vitamins, polyphenols and fatty acids [17]. Microbial, oxidation, and inflammatory disease activity processes are usably altered by phenolic components of extra virgin olive oil [20].

\section{Extra virgin olive oil (EVOO) for Systemic lupus erythematosus (SLE) \\ Increase interest is going on OIL effect on} inflammatory diseases, significant role is played by phenolics extract of EVOO in Systemic lupus erythematosus (SLE) disease this multiorgan disease is characterized by chronic deregulation of immune system which is due to multiple cytokines (B lymphocyte stimulator, IL-17, interferon and IL-6) inequal production and altered response of T- cells [10, 49].

Production of cytokines and reduces induced activation of T-cell controlled by phenolic extract from 
extra virgin olive oil probably through nuclear factor kappa $\mathrm{B}(\mathrm{NF}-\mathrm{kB})$ pathway signaling, in this way first immunomodulatory and anti- inflammatory evidence of EVOO in immune inflammatory Systemic lupus erythematosus (SLE) disease is shown [10].

\section{Aloe vera - gel: a potential choice for wound healing Aloa Vera is commonly known as Ghrit Kumari it belongs to Liliaceae family. Word Aloe vera derived from Arabic word "Alloeh" its meaning is shining bitter substance, and Vera in Latin true. All over the world Aloe vera is the most applied plant in medicinal field. It is used since biblical times for its healing effect of skin, cleansing effect and for beauty purposes [57].}

\section{Components of Aloe Vera}

Possibly there are 200 active components of aleo vera which are responsible for multiple activates of including enzymes, amino acids, sugars, vitamins, lignin, minerals, salicylic acids and saonines. The aleo vera gel contain $53 \%$ polysaccharides, $17 \%$ sugars, $16 \%$ minerals, $7 \%$ proteins, $2 \%$ phenolic compounds. Vitamins includes (Vitamins A, C and E, folic acid, Vitamin $\mathrm{B}_{12}$, and choline), 8 enzymes (alkaline phosphatase, amylase, cellulase, catalase, aliiase, bradykinase, carboxy-peptidase, peroxidase and lipase), minerals (calcium, chromium, copper, magnesium, potassium, selenium, manganese, zinc and sodium), sugars (monosaccharides: glucose/ fructose and polysaccharides: polymannose/ glucomannans), fatty acids: 4 plant steroids; campesterol, lupeol, cholesterol and $\beta$-sisosterol), hormones: auxins and gibberellins, it also contains12 anthraquinones which are phenolic compounds [70].

\section{Wound healing}

Wound healing is active process it includes three phases: $1^{\text {st }}$ phase Inflammation, $2^{\text {nd }}$ phase Dead tissue removal and $3^{\text {rd }}$ phase remodeling includes regeneration of epithelial layer and fibrous tissue formation $[55,3]$.

Present evolutionary are conducted on the wound healing characteristics of aloe vera, many researchers described that active components for process of wound healing might be a type of tannic acid or polysaccharides. Other researchers report that polysaccharides that are rich in glucomannan, mannose and growth hormone that include gerbilline do interaction with growth receptors present on surface of fibroblast these also stimulate proliferation and activity which subsequently increases collagen synthesis [3].

\section{Ginger for treatment of Migraine \\ Pharmacological potentials od Ginger as an Antient Medicine}

Ginger (Zingiber ofcinale) is the member of the Zingiberaceae family. It is commonly used spice all over the world particularly in the Asian countries. Ginger has been used as an ancient medicinal plant in India and China Americans have used wild ginger rhizome for heart beat and menstruation regulation. Ginger have clear benefit that it decreases nausea by unswervingly acting on the gastrointestinal system consequently used to reduce nausea resulting from motion sickness, surgery and chemotherapy [33]. Ginger is also recognized as a remedy for the nausea condition during pregnancy. For treatment of other gastrointestinal system problem flatulence, dyspepsia (discomfort after eating), bloating, stomach upset, loss of appetite, gas and colic. Ginger improve food digestion prescribed by Indian Ayurvedic medicinal system Indian. Ginger is widely described as a pain killer for menstrual pain, chest pain, and for betterment of low back pain [39]. Anti-inflammatory properties of ginger use for joint problems. It also used for curing cough, bronchitis and upper respiratory tract infections. Active constituent of ginger has laxative and antacid properties. Ginger lowers blood pressure and boost blood circulation by warming the body $[5,12]$.

\section{Phytochemistry of Ginger}

4000 different compounds are present in ginger. Major constituent in ginger are carbohydrates (50-70\%), lipids (3-8\%), terpenes ( $\alpha$-curcumene, $\beta$ sesquiphellandrene, $\beta$-bisabolene, $\alpha$-farnesene and zingiberene) and phenolic constituents include (paradols, shogaol and gingerol) [11]. Besides these ash, raw fiber, amino acids, vitamins (vitamin A and nicotinic acid) and minerals are also present. Volatile oils mixture like shogaols, oleoresin, gingerols are responsible for the characteristic aroma and flavor [6].

\section{Ginger in treatment of Migraine}

Migraine is normal to severe aching pain in head with symptoms of nausea, vomiting, sensitivity to sound (phonophobia), sensitivity to light (photophobia) and head movements. Migraines is one of the most frequently found pathologies of the central nervous system (CNS) which leads to decreased work productivity, performance and affect one Peron out of ten [50]. A new classification of migraines by the Headache Classification Committee of International Headache Society (IHS) in 2004 called 'migraines with aura.' 'Migraine with aura' defined as migraine in which reversible loss of sense, visual disturbance and speech occur but the actual definition of migraine kept same (https://ichd-3.org/).

\section{Mechanism of migraine}

Migraines mechanism and origin are not completely unstated. Recent research demonstrated that 5-HT (5-hydroxytryptamine) receptors activation leads to vasodilation and cause migraine [74]. In cerebral hyperemia increased blood flow toward brain is due to 5-HT receptor activation and nitric oxide synthase overexpression (NOS) in trigeminal nucleus caudalia 
and trigeminal ganglion [65]. NOS lead to the release of NO (a potent vasodilator) in neurons. NO release in neurons diffuses into the presynaptic terminal and release neurotransmitters just as CGRP (potent vasodilator) and $\mathrm{P}$ substance (pain) [22]. Cortical neuron depolarization leads to sensory or motor impairment which results in loss of speech, vision, and senses.

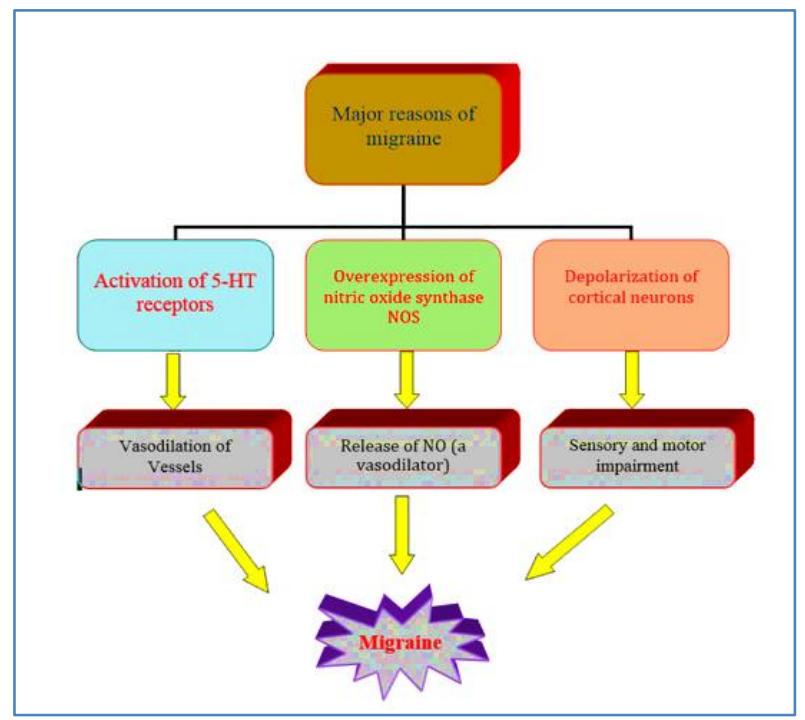

Fig- 3: Major contributing factors in Migraine

\section{Mechanism of action of ginger in curing migraine}

Several studies were done for confirmation that ginger use to treat migraine. For example, the effectiveness of ginger and sumatriptan (potent vasoconstrictor used to treat migraines) compared by Maghbooli in a group of 100 women and men who are suffering with acute migraine pain. Dried ginger powder $250 \mathrm{mg}$ or sumatriptan $50 \mathrm{mg}$ were given to the patients when the headache began, severity of headache beforehand taking the capsule and the severity of pain relief afterward recorded in participants. The results demonstrated that ginger was equally relieves headaches while minor digestive symptoms [38]. Another study that explains the efficiency of ginger for migraines was a double-blind placebo study of ginger and sublingual feverfew. In this study, sublingual feverfew/ginger capsule or a placebo are given to the patients of migraines. The results demonstrated that the $63 \%$ of patients receiving sublingual feverfew/ginger capsule found pain relief. This study demonstrated that the sublingual ginger/feverfew should be used as the first line of defense for migraines and safe [16]. Phenolic compounds are the bioactive compounds of ginger which can inhibit the production of nitric acid [21]. Ginger has also demonstrated the ability for the activation of 5-HT1A, which induces vasoconstriction and can also reduce inflammation causing redistribution of blood flow results in lessening of migraine pain [47].

Based upon above information it can be determined that bioactive compounds present in ginger inhibit NO, which helps in migraine prevention. Ginger has also been described to act as a partial Serotonin 1A (HT1A) receptor agonist, which reduces inflammation and induces vasoconstriction by inhibition of substances (CGRP, Substance P, NO) from trigeminal nerve causing redistribution of blood flow resulting in alleviation of migraine pain.

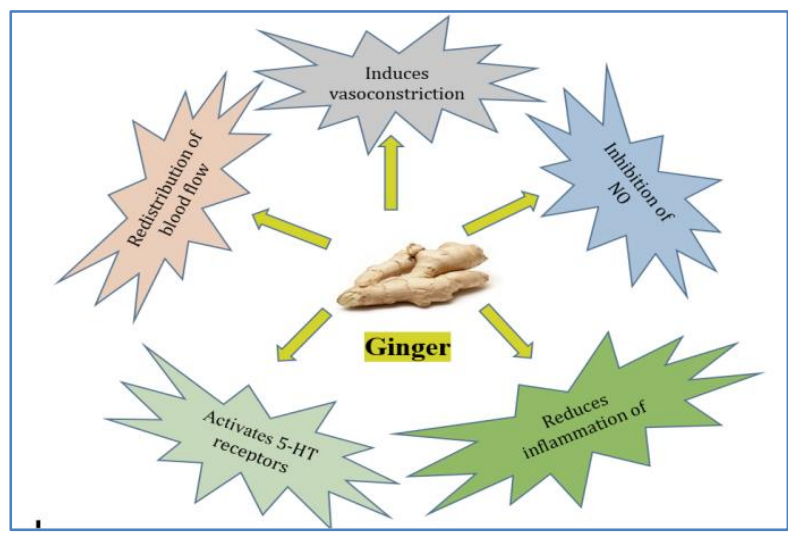

Fig-4: Role of ginger in curing migraine

\section{Role of Allium cepa in Disease Control Allium cepa}

Onion (Allium cepa. L) belongs to family Liliaceae, it comprises over 3700 species and 250 genera, onion is one of the world's oldest most widely cultivated vegetables and has excessive economic importance, especially in Asia and Europe [43, 61]. Allium cepa is one of the traditional medicinal plants. After tomatoes onion is the most important garden crop, in world. Many biological effects due to onion include antimicrobial, antidiabetic, antiplatelet, antioxidant, antibiotic, anti-inflammatory and anticarcinogenic effects [64]. Many other common illnesses including toothaches, flu, coughs, burns, heart failure, intestinal infections and kidney infections can be cured by onion use [32].

\section{Composition of Allium cepa}

The composition of onion includes $89 \%$ water, $9 \%$ carbohydrates (with $2 \%$ dietary fiber and $4 \%$ sugar) and $1 \%$ protein, and lower concentration of fat. These essential nutrients are present in lower concentration in onion. Onions give savory flavor without providing the significant caloric content, to dishes [64].

Two main phytochemicals group present in onion that have advantageous effects on human health, one is flavonoids and the other is alk (en)yl cysteine sulfoxides [61]. Flavonoids component are included among the second class of health enhancing compounds and these are active against microorganisms [32]. 16 different varieties of flavanols are present in onion, in different forms such as kaempferol, isorhamnetin, glycosylated derivatives, and quercetin and its aglycones [14]. The prime flavanols present in onion is quercetin- quercetin-4'-O- $\beta$-D-glucoside (QMG) and $3,4^{\prime}$-di-O- $\beta$-D-glucoside (QDG), these make up to 80 
$85 \%$ of total flavonoid content [43]. These flavonoids contribute in anti-inflammatory, diuretic agent and anticancer properties. The quercetin are well known for their effect on different arthritis, allergies, asthma, coronary heart disease, cancer, neurodegenerative disorders, gout and diabetic complications [35].

\section{Onion for Diabetes Mellitus}

Diabetes mellitus (DM) is endocrine metabolic disorder, indicated by an abnormally high glucose concentration in the plasma (hyperglycemia), if not treated it led to chronic degenerative diseases of the eyes, heart, nerves, kidneys and ketoacidosis. There are two more variants of DM other than self-resolving gestational DM, and these can be defined based on insulin hormone: Diabetes mellitus (DM) that is linked with low insulin level is called Diabetes mellitus type-1 (DM1) while which is linked with insulin resistance, called Diabetes mellitus type-2 (DM2) [53]. The prevalence of Type-2 DM is more than 95\%, when diagnosed diabetic cases were diagnosed [4].

Chronic high glucose levels during diabetes mellitus may involve in free radical's formation and increasing oxidative stress, that in turn damage cells. Reactive oxygen species (ROS) attack biological components of cell that alter metabolism, inflammatory mediators, and antioxidant defense mechanisms and overall favor the persistence of genetic damage and pathogenesis of disease [53].

The study led by [4] elaborated that diabetes mellitic along with other associated complications can be treated by use of onion (Allium cepa). Hence, the hypoglycemic property of onion is attributed to the occurrence of sulfur containing compounds and flavonoids such as quercetin. Quercetin mechanisms of action include alpha-glucosidase inhibition that cause inhibition of D-glucose liberation from disaccharides and oligosaccharides, as a result, glucose absorption from the intestine is delayed, hence it is considered that in controlling blood glucose levels it plays a dominant role [34].

Several experimental trials on animals indicated onion extract containing sulfur-containing compounds such as S-methlycysteine sulfoxide (SMCS) and S-allylcysteine sulpoxide, exhibit tantidiabetic effects; they increase insulin levels in blood by directly acting on pancreas. SMCS and other sulfur components present in the onion are known to control lipids in serum and tissues, blood glucose and involve in adjusting the glucose 6-phosphatase, liver hexokinase, and HMG CoA reductase (or 3-hydroxy-3methyl-glutaryl-CoA reductase) activities [4].

The glucose level is lowered by Allyl propyl disulphide, when they compete with insulin for degrading sites, later cause increase in insulin half-life
[59]. All studies on the hypoglycemic effects of onion demonstrate that all the forms of Allium cepa exert hypoglycemic effects including its freeze-dried powder oil, extract, boiled or raw onion, onion juice, or isolated active ingredients of onion such as quercetin and SMCS [4].

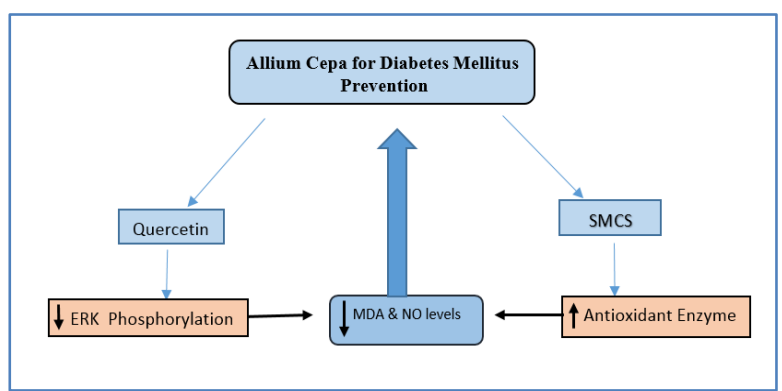

Fig-5: Mechanism of action of Allium cepa for Diabetes Mellitus

\section{Garlic and Hypertension}

Garlic as traditional medicine seems to be ancient in many cultures. Over 3000 years ago, It was reported in historic Chinese medicines. In Ayurvedic medicine it was reported over 5000 years ago. Over 3500 years ago it was reported in Africa in the historical Egyptian Codex Ebers for treating heart disease [54]. In recent times, garlic has shown efficiency in regulating multiple health marker of cardiovascular disease.

Thousands of research papers has been published to isolate the garlic bio-actives and for detail evaluation of garlic effects. Garlic extract has vital role in lowering risk of cardiovascular diseases including hypertension [23]. Garlic bio-actives components exert role in cardio vascular diseases. Garlic $(250 \mathrm{mg} / \mathrm{kg})$ has potential to lower down lipid peroxidation products and total protein carbonyl content in brain cells and have antioxidant properties.

\section{Components of garlic}

Garlic consisted upon almost $65 \%$ water, $28 \%$ carbohydrate (fructans), proteins (allinase), $2.3 \%$ organosulfuric compounds, $1.2 \%$ free amino acid (arginine) and $1.5 \%$ fiber. Allicin (diallyl thiosulfate) is one of the most active compounds present in garlic; it is responsible for pungent smell. Favorable effects of allicin are observed in case of atherosclerosis (diminishes buildup of cholesterol, lipids and calcium in medium and large arteries) and in hypertension (lowers high blood pressure). S-allylcysteine (SAC) activity enhanced during the processing of aged garlic extract, which is antioxidant and essential element of garlic [13].

\section{How garlic is antihypertensive?}

One of the major risk factor of cardio vascular disease is hypertension which is demonstrated as multi factorial disease, with high blood pressure. Systolic pressure more than $140 \mathrm{mmHg}$ or diastolic pressure 
more than $90 \mathrm{mmHg}$ [46]. In many studies conducted on garlic it is demonstrated to have antihypertensive activity which makes it one of the top studied functional food [14, 56]. Garlic help in lowering both systolic as well as diastolic blood pressure as described by Reinhart [56]. In 2 different animal models allicin help to reduce blood pressure. According to recent clinical trials conducted on patients with hypertension shows that the garlic can lower down systolic and diastolic pressure by $10-12 \mathrm{~mm}$ and $6-9 \mathrm{~mm} \mathrm{Hg}$ respectively, compared with placebo [66]. AGE (1\%) also show a relaxant effect by increasing NO production on the vasoconstriction of aorta induced by NE [71]. The comprehensive mechanism of anti-hypertensivity of garlic involves

- Reduction of oxidative stress reduces hypertension and related cardiovascular disorders.

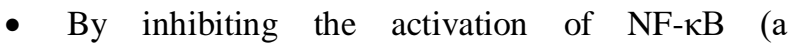
transcription factor involves in pathology of hypertension and atherosclerosis) in many types of cells including endothelial cells

- By enhancement of $\mathrm{H}_{2} \mathrm{~S}$ and influencing the activity of cystathionine c-lyase

- By augmentation of nitric oxide production.

- By inhibition of angiotensin converting enzyme which is an important part of renin-angiotensinaldosterone (RAA) system.

- By decreasing the proliferation of vascular smooth muscle cells.

\section{Fenugreek seeds extract for polycystic ovary syndrome (PCOS)}

Fenugreek seed are commonly known as 'methi' it is commonly used in Asia as food flavor enhancer [40]. The botanically Fenugreek is known as Trigonellafoenum-graecum, this short living plant belongs to Fabaceae family, its's various parts are used widely in the world as food, spice, herb and medicinal uses Recently investigations are done on its chemical composition and bio medical actions of fenugreek seeds. It used pharmaceutically for treatment of number of diseases, fenugreek seed have anticancer, antiobesity, anti- inflammatory, anti-oxidant, anti- fungal, antibacterial and help to improve women health [73].

\section{Components of Fenugreek seeds}

Fenugreek seed are rich source of minerals, protein, minerals, gum, vitamins, fiber, alkaloid, saponin, flavonoids and volatile compounds. These seeds contain bioactive compounds including $20-30 \%$ proteins, 5 - 10\% lipids (glycolipids, phospholipids, neutral lipids), and 45-60\% carbohydrates (mainly the mucilaginous, galactomannan fibers in the seed cell walls). Other important biological compound comprises pyridine type alkaloids (trigonelline), saponins, glycosides that are produced when hydrolysis occur such as steroidal sapogenins, for example diosgenin and free amino acids (4-hydroxyisoleucine) [72].

\section{Polycystic ovary syndrome (PCOS)}

Among women Poly ovarian syndrome (PCOS) is one of the most frequently occurring metabolic disorder among women, effecting every 1 in 10 women, all over the world. It the most imperative gynecological disorders among women at reproductiveage [69]. Disorders of lipid metabolism, obesity and insulin resistance also associated in many women suffering from POCS [26]. Insulin level increase due to insulin resistance which result in increased level of luteinizing hormone (LH) and follicle stimulating hormone (FSH). LH/FSH ratio in POCS patients increased than normal one [36],[1] POCS is also characterized by chronic irregular menstrual cycles, absence of ovulation, excessive facial or body hair and miscarriage [1], [69]. Insulin resistance, obesity and lipid metabolism disorder are condition present in many women suffering from POCS [26].

\section{Mechanism of action of Fenugreek seeds in POCS}

Fenugreek seeds extract shown to have antidiabetic and hypocholesterolemic effects. The $\mathrm{LH} / \mathrm{FSH}$ ratio which is about 3.16 in patients can decreased to 1.61 using fenugreek seed extract in POCS patients. This decrease in due to furocyst extract of fenugreek seeds, 90 days consumption of 2 capsules of Furocyst (fenugreek seed extract) per day show significant decrease in number and size of ovarian cyst [68].

Mammalian target of rapamycin (mTOR) signaling pathway become activated in POCS. Signaling mediated by mTOR pathway have close relationship with POCS, it paly important role in development of diabetes and cancers. mTOR pathway control cell protein synthesis, cell proliferation, autophagy and cellular metabolism [36].

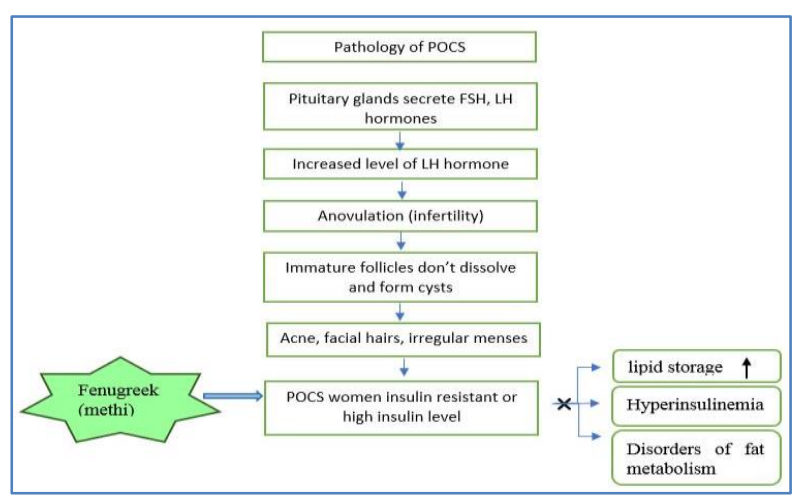

Fig-6: Mechanism of action of Fenugreek seed extract in POCS pathogenesis

\section{CONCLUSION}

Naturally active substances that present in herbs used as medicinal practice for treatment of different diseases. Plant material has potential for cure of many diseases. Some plants with their mechanism of action have role in curing disease are mentioned in this review article. Traditionally these herbs paly critical 
role in global health. Herbal use become a popular form of healthcare, these are believed to be safe having no side effect.

\section{REFERENCES}

1. Abasian, Z., Rostamzadeh, A., Mohammadi, M., Hosseini, M., \& Rafieian-kopaei, M. (2018). A review on role of medicinal plants in polycystic ovarian syndrome: Pathophysiology, neuroendocrine signaling, therapeutic status and future prospects. Middle East Fertility Society Journal.

2. Adarsh, V. B., Doddamane, K., \& Kumar, V. D. (2017). Role of carica Papaya Leaf Product in Improving the Platelet Count in Patients with Dengue Fever. Int J Res Med, 6(2), 63-68.

3. Ahmadi, F., Rezaee, S., \& Alipour, S. (2017). Formulation and evaluation of an Aloe veraLicorice combination topical gel: a potential choice for wound healing. Trends in Pharmaceutical Sciences, 3(2), 105-112.

4. Akash, M. S. H., Rehman, K., \& Chen, S. (2014). Spice plant Allium cepa: Dietary supplement for treatment of type 2 diabetes mellitus. Nutrition, 30(10), 1128-1137.

5. Alam, P. (2013). Densitometric HPTLC analysis of 8-gingerol in Zingiber officinale extract and ginger-containing dietary supplements, teas and commercial creams. Asian Pacific journal of tropical biomedicine, 3(8), 634-638.

6. Ali, B. H., Blunden, G., Tanira, M. O., \& Nemmar, A. (2008). Some phytochemical, pharmacological and toxicological properties of ginger (Zingiber officinale Roscoe): a review of recent research. Food and chemical Toxicology, 46(2), 409-420.

7. Aljohani, A. H., Alrubyyi, M. A., Alharbi, A. B., Alomair, A. M., Alomair, A. A., Aldossari, N. A., ... \& Alsaiari, L. A. Y. (2018). The Relation Between Diabetes Type II and Anemia. Egyptian Journal of Hospital Medicine, 70(4).

8. Amri, Z., Ghorbel, A., Turki, M., Akrout, F. M., Ayadi, F., Elfeki, A., \& Hammami, M. (2017). Effect of pomegranate extracts on brain antioxidant markers and cholinesterase activity in high fat-high fructose diet induced obesity in rat model. $B M C$ complementary and alternative medicine, 17(1), 339.

9. Ansari, R. M. (2016). Extract of Carica papaya L. leaves: Standardising its use in dengue fever. Indian journal of pharmacology, 48(3), 338.

10. Aparicio-Soto, M., Sánchéz-Hidalgo, M., Cárdeno, A., Lucena, J. M., Gonzáléz-Escribano, F., Castillo, M. J., \& Alarcón-de-la-Lastra, C. (2017). The phenolic fraction of extra virgin olive oil modulates the activation and the inflammatory response of $\mathrm{T}$ cells from patients with systemic lupus erythematosus and healthy donors. Molecular nutrition \& food research, 61(8).
11. Ashraf, K. A. M. R. A. N., Sultan, S. A. D. I. A., \& Shah, S. A. A. (2017). Phychemistry, Phytochemical, Pharmacological and Molecular Study of Zingiber officinale Roscoe: A Review. Int J Pharm Pharm Sci, 9(11), 8-16.

12. Balogun, F. O., AdeyeOluwa, E. T., \& Ashafa, A. O. T. (2019). Pharmacological Potentials of Ginger. In Studies on Ginger. IntechOpen.

13. Bayan, L., Koulivand, P. H., \& Gorji, A. (2014). Garlic: a review of potential therapeutic effects. Avicenna journal of phytomedicine, 4(1), 1.

14. Beesk, N., Perner, H., Schwarz, D., George, E., Kroh, L. W., \& Rohn, S. (2010). Distribution of quercetin-3, 4'-O-diglucoside, quercetin-4'-Omonoglucoside, and quercetin in different parts of the onion bulb (Allium cepa L.) influenced by genotype. Food chemistry, 122(3), 566-571.

15. Bode, A. M., \& Dong, Z. (2011). "The Amazing and Mighty Ginger". Herbal Medicine: Biomolecular and Clinical Aspects.

16. Cady, R. K., Goldstein, J., Nett, R., Mitchell, R., Beach, M. E., \& Browning, R. (2011). A DoubleBlind Placebo-Controlled Pilot Study of Sublingual Feverfew and Ginger (LipiGesicTMM) in the Treatment of Migraine. Headache: The Journal of Head and Face Pain, 51(7), 1078-1086.

17. Casas, R., Estruch, R., \& Sacanella, E. (2018). The Protective Effects of Extra Virgin Olive Oil on Immune-mediated Inflammatory Responses. Endocrine, Metabolic \& Immune Disorders-Drug Targets (Formerly Current Drug Targets-Immune, Endocrine \& Metabolic Disorders), 18(1), 23-35.

18. Charan, J., Saxena, D., Goyal, J. P., \& Yasobant, S. (2016). Efficacy and safety of Carica papaya leaf extract in the dengue: A systematic review and meta-analysis. International Journal of Applied and Basic Medical Research, 6(4), 249.

19. Chinnappan, S., Shettikothanuru Ramachandrappa, V., Tamilarasu, K., Krishnan, U. M., Balakrishna Pillai, A. K., \& Rajendiran, S. (2016). Inhibition of platelet aggregation by the leaf extract of Carica papaya during dengue infection: An in vitro Study. Viral immunology, 29(3), 164-168.

20. Cicerale, S., Lucas, L. J., \& Keast, R. S. J. (2012). Antimicrobial, antioxidant and anti-inflammatory phenolic activities in extra virgin olive oil. Current opinion in biotechnology, 23(2), 129-135.

21. Conforti, F., \& Menichini, F. (2011). Phenolic compounds from plants as nitric oxide production inhibitors. Current medicinal chemistry, 18(8), 1137-1145.

22. Edvinsson, L., Ekman, R., \& Goadsby, P. J. (2010). Measurement of vasoactive neuropeptides in biological materials: Problems and pitfalls from 30 years of experience and novel future approaches. Cephalalgia, 30(6), 761-766.

23. Eikermann-Haerter, K., \& Ayata, C. (2010). Cortical spreading depression and 
migraine. Current neurology and neuroscience reports, 10(3), 167-173.

24. Elosta, A., Slevin, M., Rahman, K., \& Ahmed, N. (2017). Aged garlic has more potent antiglycation and antioxidant properties compared to fresh garlic extract in vitro. Scientific reports, 7, 39613.

25. Furukawa, S., Fujita, T., Shimabukuro, M., Iwaki, M., Yamada, Y., Nakajima, Y., ... \& Shimomura, I. (2017). Increased oxidative stress in obesity and its impact on metabolic syndrome. The Journal of clinical investigation, 114(12), 1752-1761.

26. Gadhwal, A. K., Ankit, B. S., Chahar, C., Tantia, P., Sirohi, P., \& Agrawal, R. P. (2016). Effect of Carica papaya leaf extract capsule on platelet count in patients of dengue fever with thrombocytopenia. J Assoc Physicians India, 64(6), 22-6.

27. Galluzzo, A., Amato, M. C., \& Giordano, C. (2008). Insulin resistance and polycystic ovary syndrome. Nutrition, Metabolism and Cardiovascular Diseases, 18(7), 511-518.

28. Ganguly, S. (2017). Medicinal utility of Pomegranate fruit in regular human diet: a brief review. Int J Forestry and Horticulture, 3(1), 1718.

29. Gebicka, L., \& Banasiak, E. (2012). Hypochlorous acid-induced heme damage of hemoglobin and its inhibition by flavonoids. Toxicology in vitro, 26(6), 924-929.

30. Ghezzi, P., Jaquet, V., Marcucci, F., \& Schmidt, H. H. (2017). The oxidative stress theory of disease: levels of evidence and epistemological aspects. British journal of pharmacology, 174(12), 17841796.

31. Gumienna, M., Szwengiel, A., \& Górna, B. (2016). Bioactive components of pomegranate fruit and their transformation by fermentation processes. European Food Research and Technology, 242(5), 631-640.

32. Kar, S. K., \& Bera, T. K. (2018). Phytochemical constituents of Aloe vera and their multifunctional properties: A comprehensive review. International Journal of Pharmaceutical Sciences and Research, 9(4), 1416-1423.

33. Kasture, P. N., Nagabhushan, K. H., \& Kumar, A. (2016). A multi-centric, double blind, placebo controlled, randomized, prospective study to evaluate the efficacy and safety of Carica papaya leaf extract, as empirical therapy for thrombocytopenia associated with dengue fever. $J$ Assoc Physicians India, 64(6), 15-20.

34. Kaur, G., Gupta, V., Christopher, A. F., Bansal, R., \& Bansal, P. (2017). Kitchen phytochemicals from Allium cepa-their role in multidrug resistance. Pakistan journal of pharmaceutical sciences, 30(3), 789-792.

35. Khan, L., \& Simpson, W. G. (2019). Ginger as a Possible Alternative Treatment for Gastroparesis. Chronic Complement Altern Integra Med: CCAIM-100003, 1.
36. Kim, S. H., Jo, S. H., Kwon, Y. I., \& Hwang, J. K. (2011). Effects of onion (Allium cepa L.) extract administration on intestinal $\alpha$-glucosidases activities and spikes in postprandial blood glucose levels in SD rats model. International journal of molecular sciences, 12(6), 3757-3769.

37. Ko, E. Y., Sharma, K., \& Nile, S. H. (2016). Effect of harvesting practices, lifting time, curing methods, and irrigation on quercetin content in onion (Allium cepa L.) cultivars. Emirates Journal of Food and Agriculture, 28(9), 594.

38. Liu, A. L., Liao, H. Q., Li, Z. L., Liu, J., Zhou, C. L., Guo, Z. F., ... \& Peng, C. Y. (2016). New Insights into mTOR Signal Pathways in OvarianRelated Diseases: Polycystic Ovary Syndrome and Ovarian Cancer. Asian Pacific journal of cancer prevention: APJCP, 17(12), 5087.

39. Lo, Y. C., Chien, Y. W., \& Perng, G. C. (2017). Could inactivation of platelets be key to preventing thrombocytopenia in dengue virus infected patients?.

40. Maghbooli, M., Golipour, F., Moghimi Esfandabadi, A., \& Yousefi, M. (2014). Comparison between the efficacy of ginger and sumatriptan in the ablative treatment of the common migraine. Phytotherapy research, 28(3), 412-415.

41. Malek, V. G., Parvari, S., \& Abbassian, A. (2019). Low Back Pain Treatments in Traditional Iranian Medicine. Journal of Pharmaceutical Research International, 1-9.

42. Mani, A. (2016). Polycystic ovarian syndrome. Crit Care Obst\&Gyne, 2, 6.

43. Manthou, E., Georgakouli, K., Deli, C. K., Sotiropoulos, A., Fatouros, I. G., Kouretas, D., ... \& Jamurtas, A. Z. (2017). Effect of pomegranate juice consumption on biochemical parameters and complete blood count. Experimental and therapeutic medicine, 14(2), 1756-1762.

44. Matthaiou, C. M., Goutzourelas, N., Stagos, D., Sarafoglou, E., Jamurtas, A., Koulocheri, S. D., ... \& Kouretas, D. (2014). Pomegranate juice consumption increases GSH levels and reduces lipid and protein oxidation in human blood. Food and chemical toxicology, 73, 1-6.

45. Mollavali, M., Perner, H., Rohn, S., Riehle, P., Hanschen, F. S., \& Schwarz, D. (2018). Nitrogen form and mycorrhizal inoculation amount and timing affect flavonol biosynthesis in onion (Allium cepa L.). Mycorrhiza, 28(1), 59-70.

46. Moskaug, J. Ø., Carlsen, H., Myhrstad, M. C., \& Blomhoff, R. (2005). Polyphenols and glutathione synthesis regulation-. The American journal of clinical nutrition, 81(1), 277S-283S.

47. Nesar, S., Omer, K. R., Rizvi, S., Ali, A., Mumtaz, T., \& Usmani, M. S. A. (2018). Carica papaya; A Paired and Alternative Therapy of Dengue Fever. JOURNAL OF ADVANCES IN BIOTECHNOLOGY, 7(1), 975-983. 
48. NHLBI. What is high blood pressure. National Heart Lung and Blood Institute; 2011.

49. Nievergelt, A., Huonker, P., Schoop, R., Altmann, K. H., \& Gertsch, J. (2010). Identification of serotonin 5-HT 1A receptor partial agonists in ginger. Bioorganic \& medicinal chemistry, 18(9), 3345-3351.

50. Ojha, A., Nandi, D., Batra, H., Singhal, R., Annarapu, G. K., Bhattacharyya, S., ... \& Vikram, N. K. (2017). Platelet activation determines the severity of thrombocytopenia in dengue infection. Scientific reports, 7, 41697.

51. Paley, M. A., Strand, V., \& Kim, A. H. (2017). From mechanism to therapies in systemic lupus erythematosus. Current opinion in rheumatology, 29(2), 178-186.

52. Pan, Y., Zheng, Y. M., \& Ho, W. S. (2018). Effect of quercetin glucosides from Allium extracts on HepG2, PC-3 and HT-29 cancer cell lines. Oncology letters, 15(4), 4657-4661.

53. Paredes, P. F., González, J. B., \& Peinado, I. I. (2019). Pharmaceutical care in patients with migraine. European journal of clinical pharmacy: atención farmacéutica, 21(1), 25-32.

54. Pentewar, R., Sharma, S., Kore, P., Kawdewar, D., \& Somwanshi, S. Papaya Leaf Extract To Treat Dengue: A Review.

55. Petrou, A. L., Petrou, P. L., Ntanos, T., \& Liapis, A. (2018). A Possible Role for Singlet Oxygen in the Degradation of Various Antioxidants. A MetaAnalysis and Review of Literature Data. Antioxidants, 7(3), 35.

56. Quintero Ojeda, J. E., Aguilar-Medina, M., Olimón-Andalón, V., Jau, G., Alicia, R., Ayala Ham, A., ... \& Ramos-Payán, R. (2018). Increased Micronuclei Frequency in Oral and Lingual Epithelium of Treated Diabetes Mellitus Patients. BioMed Research International, 2018.

57. Rastogi, S., Pandey, M. M., \& Rawat, A. K. S. (2016). Traditional herbs: a remedy for cardiovascular disorders. Phytomedicine, 23(11), 1082-1089.

58. Reddy, C. U., Reddy, K. S., \& Reddy, J. J. (2011). Aloe vera-A wound healer. Asian Journal of Oral Health \& Allied Sciences-Volume, 1(1), 91.

59. Reinhart, K. M., Coleman, C. I., Teevan, C., Vachhani, P., \& White, C. M. (2008). Effects of garlic on blood pressure in patients with and without systolic hypertension: a metaanalysis. Annals of Pharmacotherapy,42(12), 1766-1771.

60. Saleh, M. Y., Chaturvedi, S., Ibrahim, B., Khan, M. S., Jain, H., Nama, N., \& Jain, V. (2019). Hearbal Detox Extract Formulation From Seven Wonderful Natural Herbs: Garlic, Ginger, Honey, Carrots, Aloe Vera, Dates, \& Corn. Asian Journal of Pharmaceutical Research and Development, 7(3), 22-30.
61. Sanches-Silva, A., L $\tilde{A}^{3}$ pez-Cervantes, J., \& Send $\tilde{A}^{3} n, R$. (2017). Aloe vera: Ancient knowledge with new frontiers. Trends in food science \& technology.

62. Santangelo, C., Vari, R., Scazzocchio, B., De Sanctis, P., Giovannini, C., D'Archivio, M., \& Masella, R. (2018). Anti-inflammatory Activity of Extra Virgin Olive Oil Polyphenols: Which Role in the Prevention and Treatment of Immune-Mediated Inflammatory Diseases?. Endocrine, Metabolic \& Immune Disorders-Drug Targets (Formerly Current Drug Targets-Immune, Endocrine \& Metabolic Disorders), 18(1), 36-50.

63. Shafiq, S., Shakir, M., \& Ali, Q. (2017). Medicinal uses of Onion (Allium cepa L.): An Overview. Life Science Journal, 14(6).

64. Shakib, Z., Shahraki, N., Razavi, B. M., \& Hosseinzadeh, H. (2019). Aloe vera as an herbal medicine in the treatment of metabolic syndrome: A review. Phytotherapy Research.

65. Sharma, A., \& Tewari, K. (2017). U.S. Patent Application No. 15/524,757.

66. Sharma, K., Mahato, N., Nile, S. H., Lee, E. T., \& Lee, Y. R. (2016). Economical and environmentally-friendly approaches for usage of onion (Allium cepa L.) waste. Food \& function, 7(8), 3354-3369.

67. Sharma, N., Mishra, K. P., Chanda, S., Bhardwaj, V., Tanwar, H., Ganju, L., ... \& Singh, S. B. (2019). Evaluation of anti-dengue activity of Carica papaya aqueous leaf extract and its role in platelet augmentation. Archives of virology, 164(4), 1095-1110.

68. Sies, H., Berndt, C., \& Jones, D. P. (2017). Oxidative stress. Annual review of biochemistry, 86, 715-748.

69. Silberstein, S. D. (2017). Topiramate in migraine prevention: a 2016 perspective. Headache: The Journal of Head and Face Pain, 57(1), 165-178.

70. Singh, R., Afroze Alam, D. V., Kumari, R., \& Tripathi, B. D. (2018). ALLIUM CEPA: A VERSATILE MEDICINAL HERB.

71. Srikiatkhachorn, A., Suwattanasophon, C., Ruangpattanatawee, U., \& Phansuwan-Pujito, P. (2002). 5-HT2A Receptor Activation and Nitric Oxide Synthesis: A Possible Mechanism Determining Migraine Attacks. Headache: The Journal of Head and Face Pain, 42(7), 566-574.

72. Stabler, S.N., Tejani, A.M., Huynh, F. (2012). Garlic for the prevention of cardiovascular morbidity and mortality in hypertensive patients. Cochrane Database Syst Rev. 2012;8:CD007653.

73. Subenthiran, S., Choon, T. C., Cheong, K. C., Thayan, R., Teck, M. B., Muniandy, P. K., ... \& Ismail, Z. (2013). Carica papaya leaves juice significantly accelerates the rate of increase in platelet count among patients with dengue fever and dengue haemorrhagic fever. Evidence-Based Complementary and Alternative Medicine, 2013. 
74. Swaroop, A., Jaipuriar, A. S., Gupta, S. K., Bagchi, M., Kumar, P., Preuss, H. G., \& Bagchi, D. (2015). Efficacy of a Novel Fenugreek Seed Extract (Trigonella foenum-graecum, FurocystTM) in Polycystic Ovary Syndrome (PCOS). International journal of medical sciences, 12(10), 825.

75. Swaroop, A., Jaipuriar, A. S., Kumar, P., \& Bagchi, D. (2016). Efficacy of a novel fenugreek seed extract (Furocyst) in polycystic ovary syndrome (PCOS). Planta Medica, 82(S 01), P1097.

76. Takashima, M., Kanamori, Y., Kodera, Y., Morihara, N., \& Tamura, K. (2017). Aged garlic extract exerts endothelium-dependent vasorelaxant effect on rat aorta by increasing nitric oxide production. Phytomedicine, 24, 56-61.

77. Van Raamsdonk, J. M., Vega, I. E., \& Brundin, P. (2017). Oxidative stress in neurodegenerative disease: causation or association?.

78. Venkata, K. C. N., Bagchi, D., \& Bishayee, A. (2017). A small plant with big benefits: Fenugreek
(Trigonella foenum-graecum Linn.) for disease prevention and health promotion. Molecular nutrition \& food research.

79. Vila-Pueyo, M. (2018). Targeted 5-HT 1F therapies for migraine. Neurotherapeutics, 15(2), 291-303.

80. Yadav, A., Singh, U., \& Charan, R. (2018). 1. Texture analysis of aleo vera-a review by anuj yadav1, upendra singh2 and ravi charan1. International research journal of chemistry, 20.

81. Yogiraj, V., Goyal, P. K., Chauhan, C. S., Goyal, A., \& Vyas, B. (2014). Carica papaya Linn: an overview. International Journal of Herbal Medicine, 2(5), 01-08.

82. Youdim, K. A., Shukitt-Hale, B., MacKinnon, S., Kalt, W., \& Joseph, J. A. (2000). Polyphenolics enhance red blood cell resistance to oxidative stress: in vitro and in vivo1. Biochimica et Biophysica Acta (BBA)-General Subjects, 1523(1), 117-122. 